Am. J. Nephrol. 1983;3:55

\title{
Contents, Vol. 3, 1983
}

Introduction 57

Renal Dysfunction in Essential Hypertension - Implications of Experimental Studies

Cowley, A.W., Jr.; Roman, R.J

59

Renal Hemodynamics in Human Subjects and in Animals with Genetic Hypertension during the

Prehypertensive Stage

Bianchi, G.; Cusi, D.; Guidi, E 73

Salt and Hypertension

Tobian, L 80

The Role of a Circulating Inhibitor of $\mathrm{Na}+-\mathrm{K}+-\mathrm{ATPase}$ in Essential Hypertension

Wardener, H.E. de; MacGregor, G.A 88

The Role of Sodium Intake, the Na+-K+ Pump and a Ouabain-Like Humoral Agent in the

Genesis of Reduced

Renal Mass Hypertension

Huot, S.J.; Pamnani, M.B.; Clough, D.L.; Haddy, F.J

The Role of Potassium in Hypertension. Discovery of Potassium as a Natriuretic and

Antihypertensive Agent

Dietz, R 100

Components of the Renin System. An Update

Hsueh,W.A 109

Inhibitors of the Renin-Angiotensin System. Effects on Blood Pressure, Aldosterone Secretion and Renal

Function

Atlas, S.A.; Niarchos, A.P.; Case, D.B

Sympatho-Adrenal System and the Kidney in Hypertension

Campese, V.M

128

Prostaglandins and the Kidney

Ferris, T.F 139

Renal Kallikrein-Kinin System. Relation to Renal Function and Blood Pressure

Mayfield, R.K.; Margolius, H.S 145

Mineralocorticoids and Hypertension

Holland, O.B.; Gomez-Sanchez, C 156

Evidence for a Role of Vasopressin in Hypertension

Sharabi, F.M.; Schmid, P.G 164

Renovascular Hypertension: An Update on Pathophysiology, Diagnosis and Treatment

Dzau, V.J.; Gibbons, G.H.; Levin, D.C 172

Hypertension in Chronic Renal Failure. Clinical Presentation, Prognosis, Pathophysiology and Treatment

Russell, R.P.; Whelton, P.K 185 